\section{Abordagem socioecológica como base para a escala local e do bairro para promover a resiliência urbana e comunitária frente às mudanças climáticas}

Socio-ecological approach as a basis for local and neighborhood scale to promote urban and community resilience to climate change

Liza Andrade*, Lara Freitas** usjt

\section{arq.urb}

número 32 | set - dez de 202 Recebido: $11 / 08 / 2021$ Aceito: $26 / 10 / 2021$

DOI: $10.37916 /$ arq.urb.vi32.548

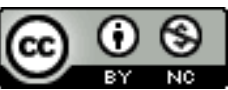

*Programa de Pós-graduação da Faculdade de Arquitetura e Urbanismo da Universidade de Brasília (PPG-FAU/UnB), Brasil, lizamsa@gmail.com

**Instituto Ecobairro do Brasil, Brasil, larafreitas@ecobairro.org.br

\section{Palavras-chave:}

Ecossistemas urbanos;

Vilas urbanas;

Ecobairros.

\section{Keywords:}

Urban ecosystems;

Urban villages;

Eco-neighborhoods.

\section{Resumo}

O objetivo deste artigo é trabalhar a abordagem socioecológica como base para a escala local e do bairro para promover a resiliência urbana e comunitária frente às mudanças climáticas. Para tanto, partiu-se da
análise dos conceitos de resiliência, de ecossistemas urbanos, urbaanálise dos conceitos de resiliência, de ecossistemas urbanos, urbanismo ecológico e de vilas urbanas (ANDRADE, 2014; FARR, 2013; PIC-
KETT, CADENASSO, MCGRATH, 2013; MARE 2008, ALEXANDER et al, 1977) que direcionam para a escala de bairro como a escala ideal para promover a resiliência para então aprofundar mais detalhadamente sobre os assentamentos e seus aspectos humanos e comunitários para a sustentabilidade, tendo como exemplos os movimentos emergentes da ecovilas e ecobairros (BARTON, 2000; FINDHORN ECOVILLAGE, 2016; FREITAS, 201 VERDAGUER, 2000)

\section{Abstract}

The aim of this article is to work the socio-ecological approach as a basis or local and neighborhood scale to promote urban and community resilience in the face of climate change. For this, we started from the analysis of the concepts of resilience, urban ecosystems, ecological urbanism and urban villages (ANDRADE, 2014; FARR, 2013; PICKETT, CADENASSO, MCGRATH, 2013; MARE 2008, ALEXANDER et al, 1977) that point to the neighborhood scale as the ideal scale to promote resilience and then go deeper into the settlements and their human and community aspects or sustainability, taking as examples the emerging movements of ecovifor sustainability, taking as examples the emerging movements of ecovillages and econeighborhoods (BARTON, 2000; FINDHORN ECOVILLAGE, 2016; FREITAS, 2016; JOUBERT; DREGGER, 2015; SILVA, 2013; VERDAGUER, 2000). 


\section{Introdução}

Este artigo trata da abordagem socioecológica necessária à sobrevivência humana no planeta como bases teóricas e metodológicas para a escala local e do bairro frente ao futuro incerto de escassez de recursos naturais, como a água potável, a redução da biodiversidade, o declínio do petróleo, as mudanças climáticas, a crise econômica global, o aumento das desigualdades sociais, pandemias, sindemias, a alta do preço dos alimentos e a fome.

Os danos irreversíveis e o grande número de perdas humanas com a pandemia bem como da biodiversidade vêm provocando a mobilização de diferentes instâncias das sociedades globalizadas. O documento da ONU (2020) "Responsabilidade compartilhada, Solidariedade Global: respondendo aos impactos socioeconômicos do COVID-19" reconhece a necessidade de aproveitar a oportunidade desta crise para fortalecer o compromisso dos países para implementar a Agenda 2030 e os 17 Objetivos do Desenvolvimento Sustentável para alcançar um futuro mais inclusivo e sustentável.

Este documento alerta que se tivéssemos avançado no cumprimento dos Objetivos de Desenvolvimento Sustentável e o Acordo de Paris sobre Mudança do Clima, nós poderíamos enfrentar melhor esse desafio. Sem dúvida alguma estamos diante de uma crise de saúde global diferente de qualquer outra desde os 75 anos de história das Nações Unidas.

Ao mesmo tempo um esboço de um relatório bombástico do Painel Intergovernamental sobre as Mudanças Climáticas ${ }^{1}$ (IPCC, sigla em inglês) órgão consultivo da Organização das Nações Unidas ( $\underline{\mathrm{ONU}}$ ) sobre o clima foi divulgado em junho de 2021, aponta que as mudanças climáticas, fruto das ações humanas, devem afetar fundamentalmente a vida na Terra já nos próximos 30 anos, mesmo que as emissões dos gases de efeito estufa sejam contidas.

Mesmo com um aquecimento de $1,5^{\circ} \mathrm{C}$, as condições vão mudar para muito além da habilidade de muitos organismos de se adaptar. No momento, todas as regiões

1O IPCC foi criado em 1988 pelo Programa das Nações Unidas para o Meio Ambiente e pela Organização Meteorológica Mundial com o objetivo de sintetizar e divulgar o conhecimento mais avançado sobre as mudanças climáticas. do planeta já são afetadas por eventos extremos como ondas de calor, chuvas fortes, secas e ciclones tropicais provocadas pelo aquecimento global

O aumento de $1,5^{\circ} \mathrm{C}$ na temperatura do planeta, segundo o relatório, resultaria em um aumento de 100 a 200\% na população afetada por enchentes no Brasil, na $\underline{\text { Co- }}$ lômbia e na Argentina, $300 \%$ no Equador e no Uruguai e $400 \%$ no Peru. Estima-se que algumas regiões - leste do Brasil, sudeste da Ásia, Mediterrâneo, centro da China - e as zonas costeiras em quase todo o mundo serão atingidas por três, quatro ou mais calamidades de uma vez: seca, ondas de calor, ciclones, incêndios florestais, inundações.

O relatório oficial do IPCC "Climate Change 2021: The Physical Science Basis" foi lançado em agosto de 2021 e quantificou pela primeira vez a responsabilidade das ações humanas irrefutáveis e irreversíveis no aumento da temperatura da Terra de $1,07^{\circ}$ na temperatura, sem precedentes em milhares, centenas de milhares de anos como o aumento contínuo do nível do mar. No entanto, segundo o relatório, se houver Reduções fortes e sustentadas na emissão de dióxido de carbono $\left(\mathrm{CO}^{2}\right)$ e outros gases de efeito estufa ainda podem limitar as mudanças climáticas.

Segundo o documento Panorama das Cidades e da Biodiversidade ${ }^{2}$, a população mundial em 2050 chegará a 9 bilhões, das quais 6,3 bilhões viverão em cidades. Até lá, o planeta terá sofrido a maior e mais rápida expansão urbana da humanidade, uma tendência irreversível de transformação para um mundo predominantemente urbano, com profundas alterações nos processos de uso do solo, da água, de energia e dos recursos naturais.

De acordo com esse mesmo documento, as áreas urbanas estão expandindo mais rapidamente que as populações urbanas, o território urbano aumentará entre 800 mil e 3,3 milhões de quilômetros quadrados até 2030.

O crescimento urbano terá impactos significativos na biodiversidade, nos habitats naturais e nos serviços dos ecossistemas dos quais a sociedade depende.

${ }^{2}$ Relatório Panorama de Cidades e Biodiversidade (Cities and Biodiversity Outlook) da Convenção sobre Diversidade Biológica (CBD), $11^{\text {a }}$ Conferência das Partes sobre Biodiversidade (COP 11) outubro de 2012. 
Recomenda-se que as áreas urbanas lidem com esses ecossistemas ${ }^{3}$, considerando seus serviços ambientais, por meio de iniciativas de "desenho e restauração" para a redução de seus impactos ambientais, com maior eficiência no uso de materiais e de energia e no uso produtivo dos resíduos.

É importante chamar a atenção para a extraordinária riqueza da biodiversidade urbana e seu papel em gerar serviços ambientais em que as populações urbanas dependem para obter alimento, água e saúde. Isso significa que é necessário integrar o campo das ciências da natureza ao campo das ciências sociais e humanas no âmbito do urbanismo, nos quais se encaixa a conexão entre ecologia e desenho urbano.

A questão que se pretende discutir neste artigo é: quais seriam as estratégias de sobrevivência, no que tange o planejamento das cidades com foco no nível do bairro, que poderiam ser trabalhadas, considerando as desigualdades sociais e os conflitos socioambientais? A macroescala do planejamento urbano regional ainda não favorece a governança local e o urbanismo sustentável ainda não consegue promover uma convergência socioecológica nos bairros pois a infraestrutura ecológica ainda é quase inacessível para as populações de baixa renda, tem servido mais como instrumento de propaganda para o urbanismo neoliberal. Como tirar lições do movimento das ecovilas e ecobairros para aplicar em assentamentos humanos de baixa renda que promovam a resiliência urbana e comunitária?

Segundo Andrade (2014), a Declaração Final da Cúpula dos Povos, na Rio+20, propõe o fortalecimento de economias locais e dos direitos territoriais para garantir a construção comunitária de economias mais vibrantes. Essas economias locais proporcionariam meios de vida sustentáveis locais e a solidariedade comunitária, componentes vitais para a resiliência dos ecossistemas, diminuindo a pegada ecológica das cidades.

Assim, a diversidade da natureza e sua diversidade cultural associada tornam-se a base para um novo paradigma de sociedade. Alguns pontos de destaque foram

${ }^{3}$ O termo "ecossistema" apareceu pela primeira vez em 1935 com Sir Arthur G. Tansley e, em 1953, Odum publica a primeira edição de Fundamentos da Ecologia como uma abordagem holística dos reivindicados na Declaração Final da Cúpula dos Povos em direção ao desenvolvimento urbano sustentável, como alternativas frente ao atual sistema.

Porém, na visão de Andrade (2014) apesar das estratégias socioeconômicas, a forma como as economias locais se estruturam no espaço urbano com reflexos na paisagem foi pouco debatida. A não ser na tenda Gaia Home, que faz parte da Rede Global das Ecovilas e do Movimento Cidades em Transição, questiona o modo de vida consumista. Porém, diferente dos grupos que lutam por seus direitos, esse grupo tem uma cultura proativa, alinhando o discurso às ações, acreditando que, na sociedade atual, já existe conhecimento, técnicas e recursos suficientes para fazer a transição para um mundo sustentável baseado na permacultura.

\section{A escala do macroplanejamento urbano regional e a necessidade do mi- croplanejamento na escala do bairro no contexto da pandemia}

Um dos grandes desafios para os planejadores do espaço urbano está em conciliar, de forma sistêmica, as demandas para a sobrevivência do ser humano água, energia, produção de alimentos, abrigos e tratamento de resíduos. Demandas essas relacionadas às densidades de ocupação e seus benefícios sociais (trabalho, ocupação e renda e acesso à saúde e educação) em equilíbrio com os ecossistemas, a paisagem e os processos naturais, como o ciclo da água urbano.

Mare (2008) acredita que no futuro, com o declínio do petróleo, como fonte de energia, as megacidades sofrerão um processo de migração reversa, com a volta das pessoas para o campo ou cidades menores, devido à escassez dos recursos naturais. Como ocorreu em algumas civilizações antigas.

Com a crise planetária da pandemia da Covid-19 já se observa a migração das pessoas da cidade para o campo, da metrópole para o interior. As cidades com certeza irão mudar após a pandemia, já se fala que a população dos grandes núcleos urbanos deverá diminuir para evitar aglomerações, pelo medo do contágio e pela busca de qualidade de vida, bem como pelo estresse dos movimentos pendulares de transporte com grande fluxo de pessoas no trânsito pelos deslocamentos intraurbanos diários e frequentes, que se dão em função de estudo e trabalho.

ecossistemas aquáticos e terrestres. Segundo Metzger (2011), o termo "ecologia da paisagem" foi introduzido pela primeira vez por um biógrafo chamado Carl Troll, quatro anos após Tansley introduzir o conceito de "ecossistema". 
Também sem contar com a tecnologia, que facilita a comunicação à distância com o trabalho em home office e reuniões remotas. Os deslocamentos internos pelas ruas da cidade se restringem a momentos de maior necessidade. No entanto, registram-se ainda mais casos de migração dos grandes centros urbanos para outras áreas urbanas menores do que para o campo, bem como a busca por casas em condomínios, bairros ou chácaras.

A pandemia atinge de forma mais expressiva e menos democrática as áreas mais pobres da cidade, com menos infraestrutura estatal, questões relacionadas ao saneamento, acesso à água, coleta de lixo, e como que isso tem se dado atualmente na realidade das favelas, segundo relatos da Fundação Oswaldo Cruz (Fiocruz), no monitoramento em comunidades pobres e favelas do Rio de Janeiro (RJ) sobre a Covid-19, Radar Covid-19 Favelas com relato dos moradores.

Por outro lado, a crise na saúde com a pandemia alavancou várias iniciativas solidárias e emergentes de governança e planejamento emergente, como, por exemplo, o Conexão Saúde, criado sem ajuda do governo, por moradores, pesquisadores da Fiocruz e ONGs na favela da Maré, reduziu em $90 \%$ as mortes por Covid com um plano de isolamento "sob medida"4 para moradores da favela, incluindo testagem em massa para Covid e atendimento médico por telefone.

Um planejamento emergente ou "de baixo para cima" também pode ser observado na favela de Paraisópolis, o "prefeito" percebeu que a melhor maneira de lidar com a pandemia sem ajuda do governo era organizar a comunidade criando comitês gestores, trazendo a responsabilidade para os moradores. Assim, foi instituído o "presidente de rua", para cuidar de 50 casas. As tarefas principais foram monitorar casos suspeitos da doença, entregar cestas básicas e kit de higiene. As mulheres foram protagonistas, cuidam da sua família e da família dos outros. Aos poucos 0 número de voluntários foi crescendo e com doações de mais de 8.000 pessoas foi consolidado o Comitê das Favelas, conseguiram comprar ambulâncias, contratar profissionais da saúde, produção de marmitas e espaços de acolhimentos em escolas para receber as pessoas contaminadas.

${ }^{4}$ https://www.bbc.com/portuguese/brasil-56919419.
Nestes casos fica claro a importância do planejamento emergente, de baixo para cima nas periferias urbanas, onde o Estado não atua. No Brasil, o planejamento urbano e a gestão urbana estão muito distantes da realidade do dia a dia das pessoas, as tomadas de decisões de planejamento são feitas por técnicos nos órgãos públicos de forma centralizada e a abordagem das políticas são completamente setorizadas.

O modelo de planejamento urbano vigente no Brasil, apesar da exigência do Estatuto da Cidade de 2001 de gestão participativa no processo, ainda é um modelo que define o macrozoneamento de "cima para baixo". As soluções de planejamento lançam diretrizes para grandes zonas urbanas, que não são emergentes de "baixo para cima", dificultando o entendimento das comunidades locais, que, em muitos casos, favorece a lógica imobiliária. Este modelo se distanciou dos estudos da forma urbana; trabalha com diretrizes gerais, não "toca o chão". Não valoriza a heterogeneidade espacial da escala mais refinada. Isso tem dificultado a interface com a abordagem ecológica científica do urbanismo, como estudos sobre ecologia urbana ou ecologia da cidade (ANDRADE, 2014).

A cidade como sistema é caracterizada por propriedades que emergem das interações das partes, definindo padrões de organização. Na visão de Capra (1996) esses padrões são entendidos como a configuração de relações características entre os componentes do sistema, que determinam as características essenciais desse sistema. Segundo Alexander et al. (1977) um padrão pode ser entendido como uma solução recorrente e cada um representa uma regra governando uma parte funcional de um sistema complexo.

O objetivo deste artigo é trabalhar a abordagem socioecológica como base para a escala local e do bairro para promover a resiliência urbana e comunitária frente às mudanças climáticas. Para tanto, partiu-se da análise dos conceitos de resiliência, de ecossistemas urbanos, urbanismo ecológico e de vilas urbanas (ANDRADE, 2014; FARR, 2013; PICKETT, CADENASSO, MCGRATH, 2013; MARE 2008, ALEXANDER et al, 1977) que direcionam para a escala de bairro como a escala ideal para promover a resiliência para então aprofundar mais detalhadamente sobre os assentamentos e seus aspectos humanos e comunitários para a sustentabilidade, 
tendo como exemplos os movimentos emergentes da ecovilas e ecobairros (BARTON, 2000; FINDHORN ECOVILLAGE, 2016; FREITAS, 2016; JOUBERT; DREGGER, 2015; SILVA, 2013; VERDAGUER, 2000).

\section{$O$ conceito de resiliência, ecossistemas urbanos e vilas urbanas}

O conceito de resiliência enfatiza a capacidade de um sistema de se adaptar às mudanças, seja de repente ou de forma gradual, no ambiente biogeofísico, em contextos e processos sociais, e recursos e controles econômicos. Na visão de Rob Hopkins, fundador do movimento Transition Towns, o conceito de resiliencia se torna mais útil à aplicação do que o conceito de sustentabilidade, uma vez que a definição de sustentabilidade em si não dá nenhuma indicação de como alcançá-lo e quais recursos são necessários à sociedade que se define como sustentável.

A definição de resiliência, trazida do campo da ecologia para o "Manual de Transição", desenvolvido por Rob Hopkin, é "a capacidade de um ecossistema de resistir a choques externos e reorganizar as mudanças a tempo, a fim de reter essencialmente a mesma função, estrutura, identidade e mecanismos de retroalimentação".

O Centro de Resiliência de Estocolmo $0^{5}$, um dos lugares onde a resiliência é estudada no âmbito acadêmico, define-a como a capacidade de lidar com a mudança e continuar a se desenvolver. $O$ conceito de resiliência pode ser empregado e compreendido para melhorar os assentamentos urbanos da humanidade. É a ferramenta pela qual os sistemas urbanos podem tentar alcançar a sustentabilidade. "Resiliência refere-se habilidade de um sistema experienciar internamente e externamente perturbações e choques gerados, mas ainda se ajustar às mudanças que resultam" (PICKETT, CADENASSO, MCGRATH, 2013, p. 8).

Pickett, Cadenasso, McGrath (2013, p. 8) acreditam que os assentamentos urbanos determinarão o futuro da humanidade. Questiona-se como serão as cidades do futuro, se elas encontrarão as necessidades básicas de todos os seus futuros residentes, se elas poderão amenizar o impacto do consumo humano de recursos, de apoio à vida tecnológica e suas consequências. Além disso, indaga-se como o me-

${ }^{5}$ É o centro internacional de pesquisa transdisciplinar que trabalha a governança de sistemas socioecológicos com ênfase especial na resiliência. Disponível em http://www.stockholmresilience.org/. tabolismo ecológico, que é a origem, fonte de recursos e suporte à vida humana, continuará funcionando e adaptado ao mundo crescentemente urbano.

Para pensar a cidade do futuro será necessário promover a integração entre designers, cientistas sociais e cientistas ambientais para discutir amplamente sobre mudanças climáticas, pico do petróleo, alta do preço dos alimentos, escassez de água potável, redução da biodiversidade, ilhas de calor, poluição, emissão de gases, inundações, tempestades, efeitos de tráfego. Será necessário promover a integração da teoria ecológica dentro das realidades práticas, sociais, estéticas do desenvolvimento urbano contemporâneo (PICKETT, CADENASSO, MCGRATH, 2013, p. 19).

O conceito de ecossistema é um conceito adequado para a compreensão do ambiente urbano como um ambiente que engloba todos os organismos urbanos no nível da comunidade, desde a estrutura física da cidade e os processos que fazem parte dela, as inter-relações das atividades humanas até mesmo de todos os níveis de vida no âmbito da cidade (SPIRN, 2011).

As cidades são ecossistemas interdependentes de outro sistema, que é seu entorno. Devem ser entendidas como um sistema que é caracterizado por propriedades que emergem das interações entre as partes. Nesse sentido, o conceito de ecossistema urbano para o desenho urbano se torna útil, considerando uma área específica na qual a comunidade de populações e organismos e o ambiente físico interagem como se fosse o "nicho" dos organismos humanos, combinando o ambiente e as características do organismo (PICKETT, CADENASSO, MCGRATH, 2013).

Como qualquer ecossistema, na visão de Spirn (2011), o ecossistema urbano considera todos os organismos que habitam dentro dele (incluindo os humanos) e suas interações entre si e com o ambiente físico, que compreende artefatos construídos, como edifícios, estradas e redes de esgotos, bem como a água, o solo e as plantas. Assim, pode-se dizer que o ecossistema urbano abrange todos os processos que sustentam os recursos naturais e humanos: culturais; fluxos de capital, pessoas e bens; fluxos de água, ar, nutrientes e poluentes. Portanto, ele é a interação dos 
componentes sociais, biológicos, físicos e do ambiente construído (ANDRADE, 2014), conforme ilustra a Figura 1.

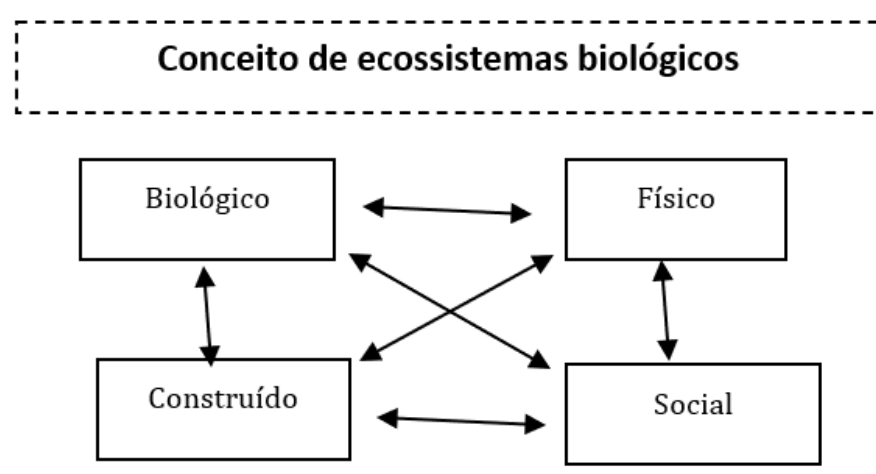

Figura 1. Conceito de Ecossistema Biológico no contexto do Ecossistema Urbano. Fonte: Andrade (2014)

Ele é um sistema dinâmico e influenciado por diferentes tipos de forças condutoras: análise espacial, contexto histórico e sustentabilidade. O urbano conota um contraste com a paisagem, caracterizada como natureza ou destinada à gestão do recurso natural e economia baseada na comodificação dos recursos naturais (PICKETT, CADENASSO, MCGRATH, 2013).

Ecossistemas urbanos contêm organismos, entidades e condições físicas, e interações entre elas. Na visão de Andrade (2014), os sistemas urbanos, com seus subsistemas, centro de cidades, subúrbios e cidades periféricas, composto de seres humanos e seus arranjos institucionais e seus artefatos, são partes dos componentes físicos e dos organismos (Figura 2).

O livro de Douglas Farr, "Urbanismo Sustentável, desenho urbano com a natureza" trouxe importante contribuição ao associar estudos sobre a compacidade (densidade) e a biofilia (acesso à natureza), apontado por Andrade (2014), que trata dos ecossistemas urbanos e os subsistemas da paisagem e da comunidade.

O urbanismo sustentável, para Farr (2013), enfatiza o apelo aos benefícios da vida no bairro, que satisfaçam as necessidades diárias a pé. Eles podem ser maiores, se houver a integração de cinco atributos: centro e limite bem definidos, compacidade, totalidade, conexão e biofilia. O pré-requisito para o design integrado é uma massa crítica de pessoas vivendo em uma vizinhança completa. Segundo Andrade (2014) esses atributos podem ser encontrados em Alexander et al. (1977), como, por exemplo, o conceito de comunidade ou vizinhança.

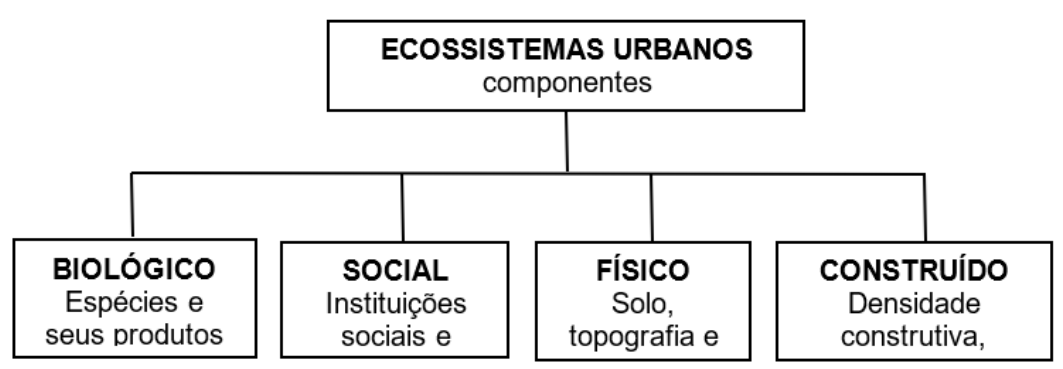

Figura 2. Componentes dos Ecossistemas Urbanos. Fonte: Andrade (2014), adaptado de PICKETT, CADENASSO, MCGRATH, 2013.

A palavra comunidade (neighborhood) é definida nos dicionários em termos sociais, espaciais e de caráter, como "pessoas que vivem perto de determinado lugar" e "uma parte de uma cidade, ou condado, frequentemente considerada como referência ao caráter ou às circunstâncias dos seus habitantes" (FARR, 2013, p. 29). Para os novos urbanistas é o "assentamento que tenha centro e limites definidos". Na linguagem da ecologia, lembrando Odum e Barret (2007, p. 5), comunidade é "toda a população que ocupa uma certa área".

Na síntese dos estudos realizada por Andrade (2014) sobre a escala de bairro ela ressalta que no urbanismo ecológico de Farr (2013) ele assegura que o tamanho ideal para um bairro deve ser adequado ao pedestre e variar entre 16 a 80 hectares. Já Alexander et al. (1977) acreditam que as cidades deveriam ser divididas em comunidades autônomas suficientemente pequenas, de 5 a 10.000 pessoas, aproximadamente de 7.000 , para que as pessoas possam ter participação no governo local e fazer a autogestão com orçamento próprio. E nos estudos de Mare (2008) ele reforça que as cidades deveriam ser divididas em vilas urbanas de 5.000 pessoas para facilitar o acesso aos recursos naturais. 
Assim, torna-se viável discutir, decidir e resolver as questões mais especificamente relacionadas com ela: uso do solo, habitação, manutenção urbana, sistema viário, parques, política de educação, previdência e segurança e serviços comunitários. Devem-se utilizar os limites geográficos naturais e históricos para marcar essas comunidades.

Para Farr (2013), o bairro pode variar em termos de tamanho e forma, mas deve satisfazer a distância limite para a caminhada de pedestres, em torno de 400 metros, como eram os bairros antes da Segunda Guerra. Para isso, a configuração da malha deve estar associada ao uso do solo, de maneira a possibilitar a conexão com o transporte público. A densidade não pode ser inferior a 17,5 unidades habitacionais por hectare para sustentar um corredor de ônibus e, de 37,5 a 50 unidades habitacionais por hectare para sustentar um serviço de ônibus elétrico ou bonde.

A integração de transporte e uso do solo gera oportunidades para as pessoas caminharem e andarem de bicicleta e favorece a acessibilidade aos cadeirantes. As densidades mais altas, com concentração de diversidade de usos, são benéficas para a vida pública e para a natureza, porque tornam possível a convivência entre as pessoas e aumentam a população de um local já urbanizado, ajudando a proteger as áreas virgens e sensíveis, concentrando em uma só parte a bacia hidrográfica.

A Figura 3, a seguir, sistematizada por Andrade (2014) ilustra os cinco atributos imprescindíveis para formar o desenho integrado dos parâmetros emergentes do urbanismo sustentável de Farr (2013).

A biofilia é o nome dado ao amor dos homens pela natureza. Segundo Farr (2013, p. 168), a falta de conexão com a natureza provoca inúmeros problemas psicológicos: estresse, transtorno de déficit de atenção e hiperatividade. A probabilidade de deslocamento a pé é três vezes maior em rotas com vegetação e árvores. A infraestrutura ecológica deve possibilitar a melhoria dos espaços públicos de convivência na cidade e da mobilidade das pessoas, seja nos caminhos para pedestres ou nas ciclovias. Em uma escala mais ampla do desenho do assentamento, deve contribuir para a mobilidade urbana no traçado viário. Por outro lado, deve melhorar as condições do ciclo da água no meio urbano e qualidade das águas, por meio de soluções de drenagem natural para evitar técnicas de macrodrenagem impactantes no solo urbano que não contribuem para evitar enchentes (ANDRADE, 2014).

\begin{tabular}{|c|c|}
\hline $\begin{array}{l}\text { Comunidade } \\
\text { Vizinhança }\end{array}$ & 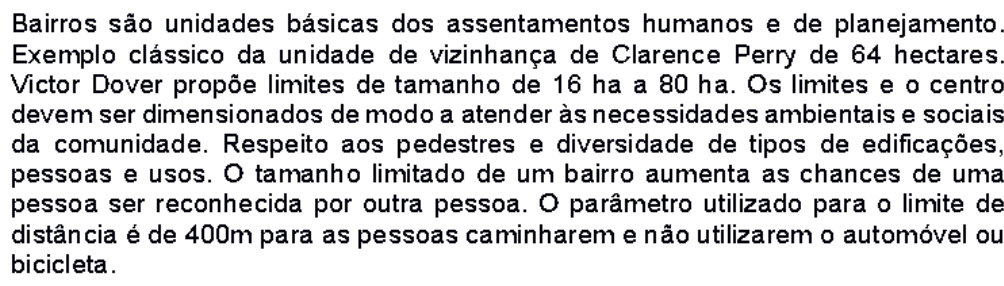 \\
\hline Compacidade & 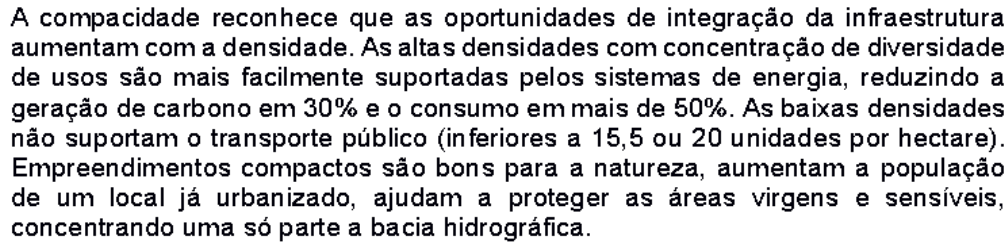 \\
\hline Diversidade & $\begin{array}{l}\text { A vizinhança aproxima as pessoas e requer a possibilidade de escolha diante da } \\
\text { diversidade de oferta de serviçso e usos que atendam a suas necessidades sem a a } \\
\text { depender de um meio de transporte. A diversidade e completude, também, referem } \\
\text { se à variedade tipológica de moradias, de maneira a acomodar pessoas e famílias } \\
\text { com diferentes modos de vida, permitindo a sua permanência na vizinhançaa mesmo } \\
\text { quando suas necessidades mudam. }\end{array}$ \\
\hline Conectividade & 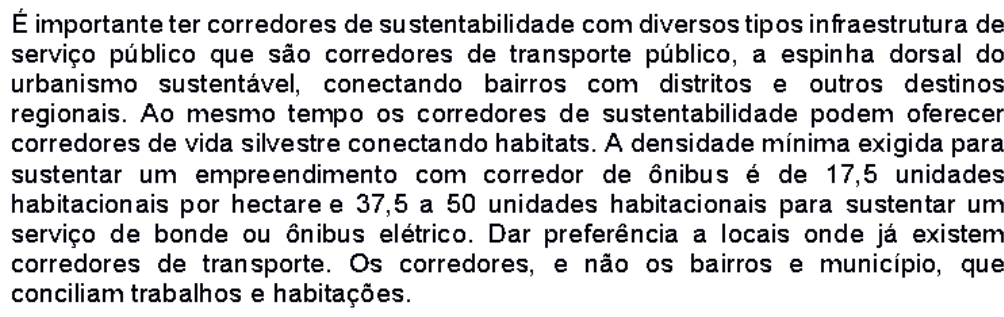 \\
\hline Biofilia & 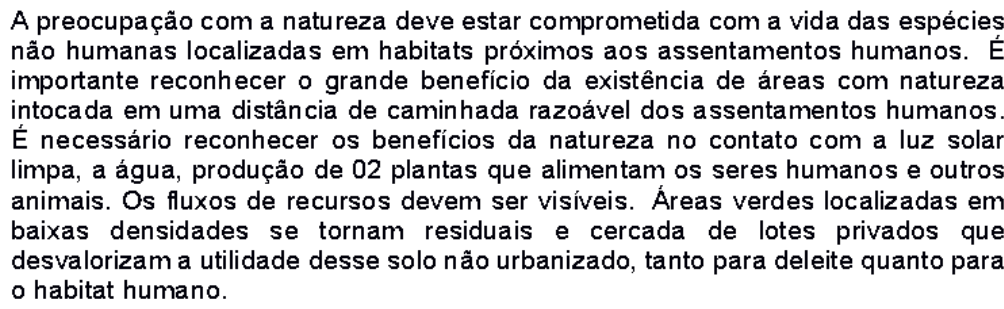 \\
\hline
\end{tabular}

Figura 3. Tabela de atributos do urbanismo sustentável sistematizados por Andrade (2014) com base em Farr (2013, p. 27 a 35) 
Outro autor apontado por Andrade (2014) que trabalha a escala de bairro, ou melhor de Vilas Urbanas é Christopher Mare (2008). Com as previsões de declínio do petróleo e escassez futura de recursos naturais propõe o modelo de Vilas Urbanas como unidades sustentáveis autossuficientes, baseadas nas aldeias tradicionais, em resposta à situação dos padrões de concentração urbana encontrados simultaneamente em diversos países. (MARE, 2008, p. 78)

À medida que há um crescimento da população também há um aumento da concentração urbana e sua densidade. Ele destaca que a sociedade contemporânea é movida pelos combustíveis fósseis, que são recursos naturais esgotáveis, mas não se percebe o esgotamento desses recursos. A consequência disso é uma severa e forçada retração do modelo vigente justamente por não conseguir sustentar-se. Surge, assim, a necessidade de traçar uma nova trajetória evolutiva em busca da sustentabilidade.

Mare (2008) se refere a esta trajetória como a "descida à aldeia urbana", pois a vila urbana se encaixaria nesse contexto como a solução sustentável. Buscando parâmetros para a proposição da aldeia urbana, o autor explora relação existente entre o regime de energia e as densidades urbanas ao longo da história.

Tomando a densidade como uma medida significativa para gerar forma física, tenta estabelecer uma densidade ideal. Constatou-se que nas cidades pré-industriais a população não ultrapassava 100 mil habitantes. Havia constância no tamanho dos assentamentos em diversas localidades nesse período. As densidades pairavam sobre um restrito intervalo até o início da revolução industrial, onde se tem a mudança do regime de energia.

O autor compara os números das cidades primitivas com os números obtidos nas cidades industriais, observando que a revolução industrial marca uma transição entre regimes energéticos. A conclusão foi que a população, o tamanho e a densidade dos assentamentos eram limitados por seu regime de energia, sendo ela um fator determinante, que acelerou o metabolismo das cidades e proporcionou o aumento e deslocamento da população. O grande aumento da população e as altas densidades tornaram as condições de vida mais precárias garantindo, por meio desse crescimento, que este padrão se tornaria insustentável. O aumento da população foi a causa do desenho excedente nas cidades, do alargamento da área dos grandes centros, com a contribuição do desenvolvimento dos meios de transporte e dos combustíveis. Estes possibilitaram o surgimento dos subúrbios, um padrão de familiar tangível para os menos afortunados devido ao afastamento da cidade.

Mare (2008) afirma que o combustível não só possibilitou esses assentamentos como também determinou a sua natureza e forma. O combustível também permitiu a verticalização das cidades modernas, levando consequentemente à densificação das grandes cidades. Apesar de se defender a verticalização como uma grande conquista, alegando que densidade planejada é uma solução mais sustentável no aspecto de reduzir a expansão urbana, questiona-se a sua viabilidade na era do pós-carbono. Isso porque as cidades com alta concentração apresentam alto consumo de energia, o que não é adequado ao quadro atual onde as fontes declinam cada vez mais.

Como as fontes de energia começam a diminuir, faz sentido que os movimentos de emigração das grandes cidades para cidades menores e para o campo sejam considerados como respostas a esta nova realidade. Estes movimentos, como as ecovilas, que apresentam baixas densidades, guiaram Mare (2008) em suas conclusões finais. Ele recomenda que o novo regime da era pós-carbono para ser sustentável, deverá utilizar drasticamente menos energia do que o regime anterior, exigindo baixas densidades.

Ele considera a proposta de Vilas Urbanas de uso misto uma solução de regeneração e reparação urbana (retrofit) para as cidades atuais como uma maneira de moldar as estruturas, padrões e processos da forma urbana, tranformado-as em comunidades sustentáveis autossuficientes, com foco na escala humana local para produção. No entanto, devem ser adaptadas ao nosso tempo para atender às necessidades essenciais primárias: produção de alimentos, água, abrigo, energia para cozinhar e para aquecimento, bem como as necessidades não tangíveis, como trabalho significativo, de interação social saudável, e de relacionamento com um poder superior, fundamentado na ecologia humana.

Mare (2008) defende uma compacidade, não no sentido da cidade compacta, mas com relação à redução da superfície urbana total. Assim seria possível uma base solar do regime de energia, que depende de colheita, transformação e extensão. E pode ser desenvolvido por meio da prática da agricultura orgânica e de sistemas agroflorestais. O sistema do novo regime vai determinar as densidades e as áreas das cidades, assim como no cenário pré-industrial (Mare, 2008). 
Conforme analisado por Andrade (2014), Christopher Mare ao propor uma população de 5.000 pessoas para Vilas Urbanas, tem como base as aldeias antigas e o "Padrão 12 - Comunidade para 7.000 pessoas", do livro "Uma linguagem de padrões" de Alexander et al. (1977, p. 71). Este padrão diz que, para que as pessoas tenham voz eficaz, a comunidade não possuir de 5.000 a 10.000 pessoas. Ele também cita Rob Krier, que coloca o limite de 10.000 pessoas para porções urbanas. $O$ que se imagina é uma reestruturação orgânica do tecido urbano em um conjunto celular autossuficiente, automantido e com interfaces metabólicas entre as unidades. Cada Vila Urbana poderia ser concebida como uma célula dentro de um tecido urbano maior.

Na visão de Mare (2008, p. 83), o planejamento ecológico é o encontro do urbanismo e da ecologia para promover a vida, a respiração da biosfera, biomas suborganizados em ecorregiões e ecossistemas. Significa preparar a atividade humana com os limites naturais estabelecidos por processos e estruturas ambientais. No entanto, segundo o autor, a educação tradicional em arquitetura e planejamento não tem a visão da transdisciplinaridade ampliada que permitiria aos teóricos apreciarem plenamente as implementações de suas propostas. As carreiras financeiras estão dentro dos limites confortáveis do progresso sequencial definido pelo status quo e com o pico do petróleo distante da realidade das populações urbanas ainda não foi sentida a urgência no nível das tomadas de decisão.

\section{Assentamentos e seus aspectos humanos e comunitários para a susten- tabilidade: Ecovilas e Ecobairros}

$\mathrm{Na}$ busca de compreender o que realmente pode ser um assentamento humano sustentável, há que se examinar não só teorias, conceitos, princípios, mas também o que está sendo colocado em prática para uma aproximação do que pode e será efetivamente um assentamento dessa natureza. Nesse sentido, as práticas emergentes colaboram para aferir as teorias e conceitos propostos nas últimas décadas.

Dentre todas as ideias e formulações, sem dúvida, há algumas que têm adquirido cada vez maior naturalidade em todos os discursos que se reclamam de ecologia urbana, suscitando um consenso cada vez maior. No âmbito territorial, a reflexão ecológica gira em torno do conceito das ecovilas e de outros conceitos similares; em um âmbito puramente metropolitano, a ideia força que converge de forma mais clara nos diversos critérios de sustentabilidade de que temos nos aproximado - é a ideia de ecobairros (VERDAGUER, 2000, p.72).

Em termos de experimentos, que utilizam as dimensões da sustentabilidade, podem-se citar também os ecobairros, principalmente a primeira geração disseminada na Europa na década de 1990. Adiante, apresenta-se, com razoável atenção, o que está sendo feito em termos de ecobairros de maneira geral quanto a conceitos, definições, princípios e seus conflitos, bem como lança-se um especial olhar para experiências consolidadas e o que está acontecendo mais recentemente.

Os ecobairros são experiências recentes onde as iniciativas mais antigas datam da década de 1970, porém ganhou força na década de 1990. São experiências que acontecem na escala local do bairro, e a maioria delas tem sido marcada pelo desenvolvimento de novos empreendimentos com conceitos de sustentabilidade ambiental, em sua maioria.

Para Newman e Jennings (2008, p.41), há muitas estratégias disponíveis: para transformar as relações econômicas e sociais, quer em nível local, quer no biorregional. Nove estratégias são descritas a seguir que poderiam ajudar as economias urbanas a tornarem-se mais focadas na comunidade e na biorregião.

Barton (2000, p.69) faz uma classificação dos ecobairros, pois pondera que este é "um termo genérico que reconhece os imperativos ecológicos e as preocupações de atingir uma sustentabilidade ambiental com adequação social e viabilidade econômica". Ele faz uma seleção eclética, de maneira "a apontar os contrastes de abordagem, de localização e escala, fazendo distinção entre os projetos rurais, urbanos e programas municipais". Propõe, então, seis categorias de ecobairros, que apresenta segundo contrastes de escala e objetivos de implementação (BARTON, 2000, p.69-81), são: Eco-Vilas Rurais, Tele-Vilas, Projetos urbanos de Demonstração, Eco-comunidades urbanas, Desenvolvimentos do "Novo Urbanismo", Municípios Ecológicos.

A concepção da cidade construída como um conjunto de peças interconectadas um mosaico - e, com alto grau de autonomia, que funcionam como um cenário cotidiano de articulação entre o local e o global, por um lado, e a ideia de regeneração ecológica da cidade como marco fundamental de atuação, por outro, são os pilares fundamentais sobre os quais descansa a ideia de Ecobairro (VERDAGUER, 2000). 
Dentre vários autores que discorrem sobre o tema, Silva (2013) aponta para os seguintes princípios e foco: comunidade compacta, diversa; prioridade aos pedestres e ao uso de bicicleta; restaurar espaços urbanos; disponibilizar habitação digna; fomentar a justiça social; apoiar a agricultura local; promover a reciclagem e reduzir a poluição e desperdício; trabalhar com empresas com foco ecológico; promover a simplicidade voluntária; aumentar a consciência sobre o ambiente local por meio do ativismo e de projetos educacionais.

Identificou-se que os aspectos sociais são uma tônica entre diferentes autores, e os aspectos ambientais ou ecológicos também são, geralmente, princípios estruturantes. A síntese dos princípios deve abranger as dimensões da sustentabilidade e incorporar cada vez mais o entendimento local e biorregional. $O$ conceito de ecobairro, apesar de não estar consolidado, torna imprescindível que sua implementação considere todas as dimensões da sustentabilidade, a partir da resiliência comunitária e urbana, tendo como fio condutor a gestão social engajada de forma permanente.

A exemplaridade e competência central que as ecovilas e comunidades intencionais trazem para que o mundo que sonhamos se torne realidade baseia-se em criar um paradigma social com comunidades de confiança em seu núcleo. Por toda a sua diversidade em comum, as ecovilas decidiram lidar com os seus problemas e desafios como uma comunidade - e continuam a fazê-lo, apesar dos conflitos, das dificuldades e dos sinais de fadiga, que inevitavelmente ocorrem (JOUBERT; DREGGER, 2015, p.22).

Ecovilas, são comunidades com estruturas sociais fortes e vibrantes, unidas por valores ecológicos, econômicos, sociais e espirituais comuns, que trabalham com o princípio simples de não retirar mais do que o planeta tem condições de repor. Ecovilas trabalham conscientemente no sentido de reduzir, progressivamente, a sua pegada ecológica (FINDHORN ECOVILLAGE, 2016).

Em um nível global, existe hoje uma necessidade cada vez mais urgente de modelos positivos que demonstram um futuro humano e planetário viável e sustentável. As ecovilas são um tal modelo, explorando estilos de vida sustentáveis, não só o ambiental, mas também em termos sociais, econômicos e espirituais. Os princípios das ecovilas podem ser aplicados igualmente a áreas urbanas e ambientes rurais e para os países industrializados e não industrializados. Elas atendem à necessidade de participação em comunidades em escala humana, enquanto nutrem e protegem o meio ambiente natural (FINDHORN ECOVILLAGE, 2016).

Após a Rio+20, a Rede Global de Ecovilas atualizou a definição de ecovila. Essa atualização resultou na seguinte definição: uma ecovila é uma comunidade intencional ou tradicional que utiliza localmente processos participativos para integrar holisticamente as dimensões ecológicas, econômicas, sociais e culturais da sustentabilidade, a fim de regenerar ambientes sociais e naturais (GEN, 2016).

As ecovilas vêm representando uma forma eficaz, acessível para combater a degradação dos ambientes sociais, ecológicos e espirituais demonstrando como podemos avançar em direção à sustentabilidade no século 21 (GEN, 2016).

A peculiaridade da proposta das ecovilas frente aos padrões tradicionais de desenvolvimento, um fator que se justifica é a relevância que essas experiências vêm adquirindo, especialmente no contexto internacional. Foram consideradas uma das 100 melhores práticas pela ONU. A ideia de ecovilas foi incorporada pelas Nações Unidas no Programa de Desenvolvimento de Comunidades Sustentáveis (SCDP), SUSTAINABLE COMMUNITY DEVELOPMENT PROGRAMME. UNDP (UNEP/96/G81).

O que há de maior valor na experiência das ecovilas não é o seu grau de excepcionalidade, ou seu porte, ou ainda o tempo que elas têm de experimentação e implementação. Isso tudo é importante, mas o aspecto mais relevante que se identifica nesses assentamentos humanos é que foram construídos fora da lógica de mercado. Foram construídos pelas pessoas e para as pessoas que vivem nesses locais, atendendo a suas necessidades individuais e comunitárias, bem como a capacidade dos recursos da sua biorregião em atender às atuais e futuras gerações. Eles trabalham suas necessidades e projetos muitas vezes em interface com o poder público e não aguardam que esses agentes venham a resolver seus desafios, mas que apoiem em determinadas situações. 
Em um estudo ${ }^{6}$ publicado em 2007 identificou que a Findhorn Foundation and Community (ecovila) em Moray, Escócia, tem a menor pegada ecológica (Figura 4) registrada em comparação com qualquer outra comunidade do mundo industrializado. A pegada ecológica é uma ferramenta para medir o consumo de recursos e a geração de resíduos, e é cada vez mais relevante para o mundo de hoje, uma vez que a eficiência energética e a sustentabilidade são aspectos críticos dos esforços para combater as mudanças climáticas (FINDHORN ECOVILLAGE, 2016).

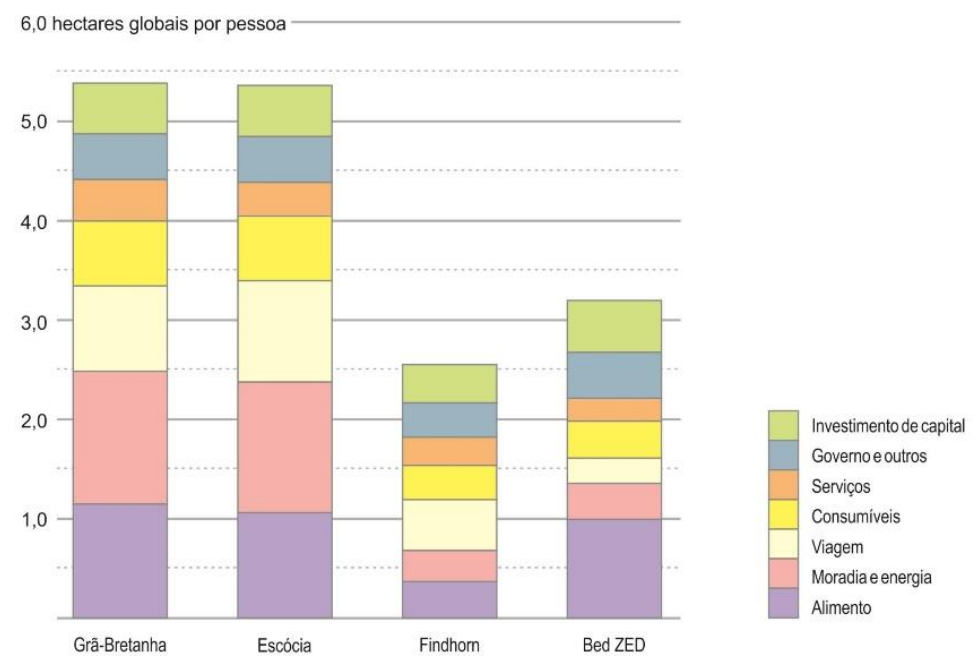

Figura 4. Gráfico da comparação da pegada ecológica entre Findhorn Foundation e BedZED. Fonte: Tinsley e George (2006).

As informações apresentadas buscam mostrar a ação holística e consistente ao longo dos anos de existência dessa experiência de Findhorn Foundation Community. A ecovila está inserida num contexto urbanizado, mesmo possuindo estruturas de agricultura. Toda a vida da ecovila, seus residentes e trabalhadores, está inserida no contexto local, da vizinhança, do município, da região e do país, e no contexto

${ }^{6} \mathrm{~A}$ pegada da comunidade é metade da média nacional, o perfil do morador médio da encovila consome apenas metade dos recursos e gera a metade do desperdício em comparação ao cidadão médio do Reino Unido (Pesquisa realizada pela Rede Global das Ecovilas - GEN-Europa, Centro de Desenvolvimento de Pesquisa Sustentável - Sustainable Development Research Centre - SDRC internacional. Portanto, não é algo utópico, mas uma experiência concreta que tem no seu propósito uma relação estreita que, de maneira comunitária, move os processos da vida.

Ainda quanto às ideias alternativas, uma das possibilidades pode ser a de remodelar cidades como redes de ecovilas urbanas. Isso nos leva à questão de como as cidades podem ser reformuladas para ser menos dependente do carro e, ao mesmo tempo, integrar as outras estratégias discutidas no procedimento de modelos (NEWMAN; JENNINGS, 2008, p.132).

Alguns dos expoentes em termos das experiências disponíveis no contexto atual se localizam prioritariamente na Europa, onde alguns autores estudados têm estudado as principais experiências de ecobairro, como já exposto anteriormente. Foram selecionados pela perspectiva de poderem contribuir, por similaridade ou diferenciação, com outras realidades, considerando aspectos de planejamento urbano, de gestão e de gerar aprendizados na interação com políticas públicas locais (FREITAS, 2016).

A cidade de Freiburg possui planos de infraestrutura verde em duas escalas. $\mathrm{Na}$ escala do município, determina redes de áreas de conservação ( $46 \%$ de seu território é coberto pela Floresta Negra) e agrícolas, que entremeiam os espaços urbanizados, utilizados para transporte de baixo impacto em CO2. Na escala local, há um trabalho conjunto com os moradores para manter a consistência com o plano maior, priorizando as pessoas, a biodiversidade e as águas (HERZOG, 2013).

Newman e Jennings (2008, p.158) também destacam que Freiburg foi liderada por "aprender fazendo". O processo de trabalhar para fora como fazer uma cidade solar, sustentável, mais resiliente exige aprender fazendo.

$\mathrm{Na}$ abordagem chamada de "Learning by Planning", Frieburg deve ter aprendido muito no percurso de desenvolvimento de Vauban; criaram uma abordagem totalmente nova para o desenvolvimento urbano sustentável, estabelecendo metas fortes e depois demandando a ONG (Fórum Vauban) para compor o processo de

- em Forres com apoio do Instituto Ambiental de Estocolmo - Stockholm Environment Institute - e Universidade de York (FINDHORN ECOVILLAGE, 2016). 
implementação. Freiburg sabia que não havia nenhum modelo de como fazer uma cidade carbono neutro, livre de carros - eles tiveram que inventá-la. Nos círculos acadêmicos essa abordagem de novas formas de governança é chamada de "aprendizagem política".

Vauban é em um projeto de regeneração urbana de uma área que abrigava uma base militar francesa, adquirida pela municipalidade, para viabilizar a compra de lotes para particulares. O bairro almejava alcançar uma população de 5.000 habitantes, com 600 novos empregos em uma área de 38ha, totalizando uma densidade de 130 hab/ha (ARAÚJO E ANDRADE, 2014). Segundo Frey et al. (2010, s.p), já em 2006 a população era de 4.588 habitantes, distribuídos em uma área de 32ha, conformando uma densidade populacional de 141 hab/ha. Em comparação a outro bairro verde de Freiburg, Rieselfeld, que em 2008 possuía uma densidade de 117 hab/ha (população de 8.200 pessoas, em 70ha), a densidade apresentada por Vauban se sobressai.

Esse número está longe de ser o ideal para os estudiosos da dimensão sociológica para a "cidade viva", que tem como parâmetros a densidade proposta por Jane Jacobs, de 247 moradias por hectare, aproximadamente 700 hab/ha. Porém, para Christopher Mare essa densidade está acima da proposta para as vilas urbanas mais sustentáveis.

\section{Considerações finais}

Dentre as conclusões que os estudos e práticas trazem face ao cenário atual, fica evidente que:

- é fundamental o aprimoramento da legislação e dos instrumentos urbanísticos para que deem suporte aos processos em escala local (da rua, quarteirão, agrupamento de quadras, bairro) e esta tenha os quesitos para favorecer um resultado de sucesso no planejamento, na implantação e operação de um assentamento humano sustentável para alcançar os ODS da Agenda 2030, em especial de ecobairros, seja em áreas centrais ou periféricas. Os instrumentos podem estar alinhados aos projetos da Fiocruz sobre Territórios Saudáveis e Sustentáveis nas periferias urbanas.

- as instituições públicas precisam promover o planejamento nas várias escalas e de forma integrada, reconhecer e incluir a escala local ou do bairro, dando atenção tanto às políticas quanto às ferramentas e aos instrumentos específicos para que se viabilize uma condução apropriada e inclusiva. Um caso clássico, é o Plano Diretor Estratégico da cidade de São Paulo, que tem instrumentos previstos e não favoreceu para que fossem colocados em prática. Estamos na iminência de ocorrer uma revisão deste plano e novamente não se demonstra interesse em valorizar e aproveitar as contribuições ímpares advindas da escala dos bairros na composição do planejamento efetivo e mais assertivo da cidade como um todo.

- criar ou fomentar instâncias da sociedade civil específicas de estudo permanente dessa escala local, acompanhada de fórum permanente para estreito diálogo e participação da população. Exemplo embrionário disso é o CADES (Conselho Regional de Meio Ambiente, Desenvolvimento Sustentável e Cultura de Paz), em São Paulo. Mas, para isso, poderia ser implantada uma metodologia, com mecanismos de interação e alocação de recursos atrelados ao orçamento municipal, bem como mais dedicação dos seus eleitos para que se viabilizasse maior capacidade de realização. Seria um impulsionador interessante para que um processo de ecobairro pudesse iniciar e amadurecer nesse contexto em que se trata de assentamentos existentes ou de renovação urbana, que são os cenários e contextos mais recorrentes das cidades.

- a abordagem educacional que esses processos requerem, portanto, os processos comunitários que visem dar suporte para um processo de (des)envolvimento para co-criação de assentamentos humanos sustentáveis, reconhecer que o processo educativo é uma tônica e essencial ao processo para concretizar as estratégias e soluções prevista nos princípios de sustentabilidade.

Portanto, isso evidencia a lacuna e a falta de políticas de fomento e apoio para que se amplie esse tipo de ação e possam ser elas mais estruturadas e em maior número mediante oportunidades de financiamentos. A ação do Grupo de Trabalho e Pesquisa Ecobairros da Plataforma Arquitetura e Biosfera da Escola da Cidade experimenta um caminho que reúne os olhares dos professores-pesquisadores, do legislativo e dos ativistas num processo de pesquisa-ação para a discussão e proposição ou aprimoramento de políticas públicas relacionadas à assentamentos humanos sustentáveis na cidade de São Paulo, em especial o diálogo sobre ecobairros. 


\section{Referências}

ALEXANDER, Christopher; ISHIKAWA Sara; Murray, SILVERSTEIN; JACOBSON, Max; FIKSDAHL-KING, Ingrid; ANGEL, Shlomo. A Pattern Language. New York: Oxford University Press, 1977.

ANDRADE, Liza M.S. de. Conexões dos padrões espaciais dos ecossistemas urbanos, a construção de um método com enfoque transdisciplinar para o processo de desenho urbano sensível à água no nível da comunidade e da paisagem. Tese (Doutorado em Ciências Aplicadas), Pós-Graduação da Faculdade de Arquitetura e Urbanismo, Universidade de Brasília, Brasília, 2014. 544f.

ARAÚJO, Lara Agostinho; ANDRADE, Liza Maria Souza de Andrade. De Vauban para o mundo: trazendo a resiliência urbana do contexto local para o nível planetário. In: 6o Congresso Luso-Brasileiro para o Planejamento Urbano Regional Integrado, sustentável - Pluris, 2014, Lisboa - Portugal. Anais... Lisboa: Universidade Técnica de Lisboa, 2014.

FARR, Douglas. Urbanismo sustentável. São Paulo: Bookman Editora, 2013.

FINDHORN ECOVILLAGE. Disponível em: <http://www.ecovillagefindhorn.com/>. Acesso em: 1. ${ }^{\circ}$ fev. 2016.

FREITAS, Lara Cristina Batista. Análise de assentamentos humanos sustentáveis: experiências relevantes de ecobairros e ecovilas. 2016. Dissertação (mestrado) - Pontifícia Universidade Católica do Paraná. Curitiba, 2016.

Frey, H., Bagaeen, S., Giachis, C., Faria, P. New approaches in urban development, presentation on Energy Days, Series 1, Day 8: Geothermal Energy \& Energy in the Built Environment, Eindhoven University of Technology, Netherlands, Part 3, 11 Fevereiro 2010.

GLOBAL ECOVILLAGE NETWORK (GEN). Avaliação da Sustentabilidade Comunitária (ASC) - Community Sustainability Assessment (CSA). Nazaré Paulista, 2003. Disponível em: <http://sites.ecovillage.org/sites/default/files/files/csa-previous.pdf >. Acesso em: 20 maio 2016.

HERZOG, Cecília Polacow. Cidades Para Todos - (re)aprendendo a Conviver Com a Natureza. Rio de Janeiro: Editora MAUAD, 2013.
JOUBERT, Kosha; DREGGER, Leila. Ecovillage: 1001 ways to heal the planet. Devon: Triarchy Press, 2015.

MARE, Christopher. An Historical survey of urban densities as a consequence of energy regime: descent into the urban village. In: Ecocity 7, São Francisco, Califórnia - USA, 2008. Proceedings... São Francisco: Nob Hill Masonic Center, 2008.

NETTO, Vinicius de Moraes; SABOYA, Renato. A urgência do planejamento: a revisão dos instrumentos normativos de ocupação urbana. Arquitextos - Vitruvius, n. 125.02, 2010. Disponível em: https://vitruvius.com.br/revistas/read/arquitextos/11.125/3624. Acesso em: 14.07 .21

NEWMAN, Peter; JENNINGS, Isabella. Cities as Sustainable Ecosystems: principles and pratices. Washington/EUA: Island Press, 2008.

ODUM, Eugene P.; BARRET, Gary W. Fundamentos de Ecologia. Tradução da 5a edição norte-americana. São Paulo: Cengage Learning, 2007.

PICKETT S.T.A., CADENASSO M.L., MCGRATH Brian. Ecology of City as a Bridge to Urban Design. In: PICKETT S.T.A., CADENASSO M.L., MCGRATH Brian: Resilience in Ecology and Urban Design. LinkingTheory and Practice for Sustainable Cities. Springer Science. New York, 2013.

SILVA, Marco Manuel Ribeiro da. Eco-bairros: análise de casos internacionais e Recomendações para o Contexto nacional. 2013. 124f. Dissertação (Mestrado) Universidade Nova de Lisboa, Lisboa, 2013.

SUSTAINABLE COMMUNITY DEVELOPMENT PROGRAMME. UNDP (UNEP/96/G81).

TINSLEY, Stephen; GEORGE, Heather. Ecological footprint of the Findhorn Foundation and community. Forres: Sustainable Development Reserarch Centre, 2006.

VERDAGUER, Carlos. De la sostenibilidad a los ecobarrios. Documentación Social, v.119, 2000. 